\title{
Periodic medical check-up among residents of three Nigerian South- western States
}

\author{
S.O. Usman ${ }^{1}$, O. Edet-Utan ${ }^{2}$, A. Suleiman ${ }^{3}$, I.N. Isola ${ }^{4}$, A. Ojogbede ${ }^{5}$, N.O. Akintayo-Usman 6 , \\ O.J. Fatunmbi ${ }^{7}$, A.S. Adu ${ }^{4}$ \\ ${ }^{1}$ Department of Clinical Laboratory, Equitable Health Access Initiative, Akure, Nigeria. \\ ${ }^{2}$ Department of Public Health, Adeleke University, Ede, Nigeria. \\ ${ }^{3}$ Department of Strategic Information, Institute of Human Virology Nigeria, Lagos, Nigeria. \\ ${ }^{4}$ Department of Biochemistry, Federal University of Technology, Akure, Nigeria. \\ ${ }^{5}$ Department of Strategic Knowledge Management, Equitable Health Access Initiative, Akure, Nigeria. \\ ${ }^{6}$ Department of Medical-Surgical Nursing, Osun State School of Nursing, Osogbo, Nigeria. \\ ${ }^{7}$ Department of Laboratory Services, Union Diagnostics, Osogbo, Nigeria.
}

\begin{abstract}
Objectives: General medical examination is a common form of preventive medicine. Periodic medical check-up generally involves thorough history, physical examination and screening of asymptomatic persons by physicians on a regular basis as part of a routine health care process. Periodic medical check-up is considered effective in preventing illness and promoting health and reducing morbidity and mortality. This study is therefore designed to determine the knowledge, attitude and practice of periodic medical check-up among residents of Osun, Ondo \& Ekiti States of Nigeria. It is also to determine the influence of educational status on its practice and compare the outcomes in the three states. Materials \& Methods: The cross-sectional survey study utilizing both qualitative and quantitative method of data collection was conducted at various locations across the three states. The locations included those of public servants, private sector workers, artisans, traders, business men/women,
\end{abstract}

farmers, among others. Results: 1200 consenting residents participated in the study in each of the three states. $518(43.2 \%)$ of the respondents in Ondo State are males while 682 (57.8\%) are females. $465(38.8 \%)$ of the respondents in Ekiti State are males while 735 $(61.2 \%)$ are females. $494(41.2 \%)$ of the respondents in Osun State are males while $706(59.8 \%)$ are females. The mean age in Ondo, Ekiti \& Osun were $43.8 \pm 10.7$ years, $44.6 \pm 11.5$ years and $41.7 \pm 10.1$ years respectively. $89.2 \%, 88.3 \%$ and $87.4 \%$ of the respondents are aware of periodic medical check-up in Ondo, Ekiti and Osun states respectively. Conclusion: There is high level of awareness of periodic medical checkup in all three states but the level of practice of routine medical checkup is low. The majority of the respondents probably don't practice it because their health insurance plan does not cover the medical checkup or due to individual/organizational financial constraints.

(Keywords: periodic medical check-up, Ekiti, Ondo, Osun, practice)
Corresponding Author: Saheed Opeyemi Usman

Address: Department of Clinical Laboratory, Equitable Health Access Initiative, Akure, Nigeria

E-mail: senatorhopsy@yahoo.com
Başvuru Tarihi/Received: 06-01-2016

Kabul Tarihi/Accepted: 11-02-2016 


\section{INTRODUCTION}

General medical examination is a common form of preventive medicine involving visits to a general practitioner by well feeling adults on a regular basis. This is generally yearly or less frequently. It is known under several other names, such as the periodic health evaluation, annual physical, comprehensive medical examination, general health check, or preventive health examination [1]. It typically involves a medical history, which is a brief or complete physical examination and sometimes laboratory tests. Some more advanced tests include ultrasound and mammography.

Periodic medical check-up generally involves thorough history, physical examination and screening of asymptomatic persons by physicians on a regular basis as part of a routine health care process [2]. Periodic medical check-up is considered effective in preventing illness and promoting health and reducing morbidity and mortality [3]. People around the world pay varying levels of attention to health issues and give differing levels of priority regarding medical check-up. During periodic or routine medical checkup some of the non-communicable diseases such as cancer (breast, prostate, cervical), hypertension, diabetes mellitus, among others, can be detected and any deviation from good health is noticed and managed in the form of preventive or curative services thereby reducing the mortality associated with them [4].

It is essential to have periodic medical examination as various chronic diseases have a hefty socio-economic burden on individuals affected [5]. Thorough medical examination is necessary and its frequency increases if there is a health problem that requires continuing care. Factors that are nonmodifiable like age and family history of certain diseases determine the check-up or screening that one requires. Likewise the presence of modifiable risk factors like smoking, consumption of alcohol, unhealthy lifestyle including sedentary lifestyle and diet, are all paramount in determining the frequency of check-up [6]. Generally, in developing countries including Nigeria, where the practice of periodic medical check-up is poor, very few studies have been conducted on periodic medical checkups. A 2012 study on the perception and practice of periodic medical checkup by traders in South East Nigeria reported that $74.9 \%$ were aware of periodic medical checkup. $61.2 \%$ have their major source of information to be through friends with $18.2 \%$ being through mass media. The commonest known type of medical checkup was general examination (60.7\%) and blood pressure measurement (55.4\%). About $63.8 \%$ feel everybody needs medical checkup. Most (85.5\%) feel medical checkups can improve their work efficiency. The study concluded that there is a high level of awareness of periodic medical checkup, but a very low level of practice among the group [7]. Another study on the periodic medical checkup, knowledge and practice in a community in South West Nigeria, showed that $62 \%$ have ever heard of periodic medical check-up, $79 \%$ of those who have heard had ever had it done and only $48.2 \%$ among those who had ever done it had frequent medical check-up. $50 \%$ had general medical examination, $32.2 \%$ had blood pressure check, $6.9 \%$ had visual check, $6.2 \%$ had dental check while $4.6 \%$ checked their blood sugar. $67.6 \%$ did medical check-up every six months, $9.6 \%$ did yearly while $8.1 \%$ did every two years [8]. The uptake of periodic medical check-up or preventive screening services has been shown to be poor in many developing countries and sub-optimal in countries like the USA and Britain despite its importance and potential benefits [9]. Everyone is expected to have a medical check-up at time interval 
especially as he or she progresses with age as it gives a better assessment of the individual's health status. This study is therefore designed to determine the knowledge, attitude and practice of periodic medical check-up among residents of Osun, Ondo \& Ekiti States of Nigeria. It is also to determine the influence of educational status on its practice and compare the outcomes in the three states.

\section{MATERIALS AND METHODS}

\section{STUDY SITE/SUBJECT SELECTION/ STUDY DESIGN}

The cross-sectional survey study utilizing both qualitative and quantitative method of data collection was conducted at various locations across the three states. The locations included those of public servants, private sector workers, artisans, traders, business men/women, farmers, among others. Participation was voluntary and informed consent was obtained by participants' signing the consent form attached to the questionnaire. Names of participants were not included in the information requested. The structured questionnaire was administered consecutively to 1200 consenting residents by interviewer in each of the three states. Simple random sampling was used to randomly select the required number of participants till the required number of willing participants is recruited, following the selection of two major towns in each of three senatorial districts in each state. The questionnaire contained sections including socio-demographic data, as well as, information about the knowledge and practice of periodic medical check-up. The data collected through the questionnaire were statistically analyzed using Statistical Package for the Social Sciences (SPSS) for windows version 20.0 software. Frequency counts were generated for all variables and statistical tests of significance was performed with chi- square test. Significance was fixed at $\mathrm{P}<0.05$ and highly significant if $\mathrm{P}$ $<0.01$

\section{SAMPLE SIZE}

Sample size calculation was done using 95\% confidence interval and $3 \%(0.03)$ degree of precision. The formula for sample size when population is more than 1000 is: $n=Z 2 P Q / d 2$ $[10,11]$. An online sample size calculator was used to calculate the number of respondents to be included in the study based on an estimated population size of the residents of the each State using a 3\% degree of precision or margin of error and $95 \%$ confidence level, which resulted a minimum required sample size (n) of 1067 respondents in each of the three states [12].

$$
\begin{aligned}
\mathbf{n} & =\mathbf{Z}^{2} \mathbf{P Q} / \mathbf{d}^{\mathbf{2}} \quad \text { Where: } \\
\mathbf{n} & =\text { minimum sample size, } \\
\mathbf{Z} & =\text { standard normal deviation at } 95 \%
\end{aligned}
$$
confidence interval which is 1.96 ,

$\mathbf{d}=$ degree of precision

$\mathbf{P}=$ proportion of the target population or prevalence

$$
\mathbf{Q}=\text { alternate proportion (1-P) }
$$

\section{RESULTS}

\section{SOCIO-DEMOGRAPHIC DATA}

1200 consenting residents participated in the study in each of the three states. 518 $(43.2 \%)$ of the respondents in Ondo State are males while 682 (57.8\%) are females. 465 (38.8\%) of the respondents in Ekiti State are males while 735 (61.2\%) are females. 494 (41.2\%) of the respondents in Osun State are males while $706(59.8 \%)$ are females. The mean age in Ondo, Ekiti \& Osun were $43.8 \pm$ 10.7 years, $44.6 \pm 11.5$ years and $41.7 \pm 10.1$ years respectively. 719 (59.9\%), 612 (51.0\%) \& $691(57.6 \%)$ of the respondents in Ondo, Ekiti \& Osun respectively have their marital status as married. In Ondo State, 336 (28.0\%) of the respondents are into trading/business, 281 (23.4\%) are public servants, with 150 (12.5\%) artisans while in Ekiti State, 231 (19.3\%) are into trading/business, 310 (25.8\%) are public 
Table 1: Educational Status Of Respondents

\begin{tabular}{|l|l|l|l|}
\hline \multirow{2}{*}{ EDUCATIONAL STATUS } & ONDO STATE & EKITI STATE & OSUN STATE \\
\cline { 2 - 4 } & Frequency $(\%)$ & Frequency $(\%)$ & Frequency (\%) \\
\hline No formal education & $113(9.4 \%)$ & $47(3.9 \%)$ & $57(4.8 \%)$ \\
\hline Primary education & $171(14.3 \%)$ & $84(7.0 \%)$ & $70(5.8 \%)$ \\
\hline Secondary education & $271(22.6 \%)$ & $231(19.3 \%)$ & $122(10.2 \%)$ \\
\hline $\begin{array}{l}\text { National Certificate in } \\
\text { Education/Ordinary National } \\
\text { Diploma (NCE/OND) }\end{array}$ & $320(26.7 \%)$ & $402(33.5 \%)$ & $350(29.2 \%)$ \\
\hline $\begin{array}{l}\text { Higher National } \\
\text { Diploma/Bachelor's Degree } \\
\text { (HND/BSc) }\end{array}$ & $195(16.3 \%)$ & $311(25.9 \%)$ & $470(39.2 \%)$ \\
\hline $\begin{array}{l}\text { Master's Degree } \\
\text { PhD Degree }\end{array}$ & $46(3.8 \%)$ & $51(4.3 \%)$ & $83(6.9 \%)$ \\
\hline
\end{tabular}

PERIODIC MEDICAL CHECK-UP PARAMETERS

Table 2: Information About Medical Check-Up Parameters

\begin{tabular}{|l|l|l|l|l|l|l|}
\hline \multirow{2}{*}{ PARAMETERS } & \multicolumn{2}{l|}{ ONDO STATE } & \multicolumn{2}{l|}{ EKITI STATE } & \multicolumn{2}{l|}{ OSUN STATE } \\
\cline { 2 - 7 } & Frequency & Percentage & Frequency & Percentage & Frequency & Percentage \\
\hline $\begin{array}{l}\text { Aware of periodic medical } \\
\text { check-up }\end{array}$ & 1070 & $89.2, \%$ & 1060 & $88.3 \%$ & 1049 & $87.4 \%$ \\
\hline $\begin{array}{l}\text { Ever deliberately had any } \\
\text { routine periodic medical } \\
\text { check-up }\end{array}$ & 353 & $29.4 \%$ & 624 & $52.0 \%$ & 434 & $36.2 \%$ \\
\hline $\begin{array}{l}\text { Think everybody needs a } \\
\text { medical check-up }\end{array}$ & 1027 & $85.6 \%$ & 1008 & $84.0 \%$ & 1050 & $87.5 \%$ \\
\hline $\begin{array}{l}\text { Think males need medical } \\
\text { check-up more than } \\
\text { females }\end{array}$ & 280 & $23.3 \%$ & 213 & $17.8 \%$ & 196 & $16.3 \%$ \\
\hline $\begin{array}{l}\text { Think females need } \\
\text { medical check-up more } \\
\text { than males }\end{array}$ & 427 & $35.6 \%$ & 487 & $40.6 \%$ & 494 & $41.2 \%$ \\
\hline $\begin{array}{l}\text { Think periodic medical } \\
\text { check-up will improve } \\
\text { health }\end{array}$ & 1038 & $86.5 \%$ & 976 & $81.3 \%$ & 1025 & $85.4 \%$ \\
\hline $\begin{array}{l}\text { Covered by health } \\
\text { insurance plan }\end{array}$ & 259 & $21.6 \%$ & 306 & $25.5 \%$ & 295 & $24.6 \%$ \\
\hline $\begin{array}{l}\text { Health insurance plan } \\
\text { cover periodic medical } \\
\text { check-up }\end{array}$ & 209 & $17.4 \%$ & 286 & $23.8 \%$ & 263 & $21.9 \%$ \\
\hline
\end{tabular}


A vast majority of respondents know that there is need to have a periodic medical checkup, but vary in terms of frequency. In Ondo State, $368(30.7 \%)$ of the respondents think it should be done monthly, 509 (42.4\%) think three monthly is adequate, 143 (11.9\%) preferred six monthly while $63(5.3 \%)$ said it should be done annually. In Ekiti State, 362 $(30.2 \%)$ of the respondents think periodic medical check-up should be done monthly, 458 (38.2\%) think three monthly is adequate, 161
(13.4\%) preferred six monthly while 90 (7.5\%) said it should be done annually. In Osun State, $384(32.0 \%)$ of the respondents think periodic medical check-up should be done monthly, 359 (29.9\%) think it should be done three monthly, 199 (16.6\%) preferred six monthly while 77 $(6.4 \%)$ said it should be done annually. Those that have not deliberately undertaken any form of periodic medical check-up across the three states was due to reasons ranging from financial challenge, busy work schedule and steady health condition.

Table 3: Respondents Monthly Income

\begin{tabular}{|l|l|l|l|}
\hline \multirow{2}{*}{$\begin{array}{l}\text { MONTHLY INCOME } \\
(\text { IN NAIRA) }\end{array}$} & ONDO STATE & EKITI STATE & OSUN STATE \\
\cline { 2 - 4 } & Frequency $(\%)$ & Frequency $(\%)$ & Frequency $(\%)$ \\
\hline$<\# 5,000$ & $78(6.5 \%)$ & $112(9.3 \%)$ & $117(9.8 \%)$ \\
\hline$\# 5,001-\# 18,000$ & $164(13.7 \%)$ & $145(12.1 \%)$ & $150(12.5 \%)$ \\
\hline$\# 18,001-\# 30,000$ & $242(20.2 \%)$ & $148(12.3 \%)$ & $151(12.6 \%)$ \\
\hline$\# 30,001-\# 50,000$ & $280(23.3 \%)$ & $176(14.7 \%)$ & $120(10.0 \%)$ \\
\hline$\# 50,001-\# 80,000$ & $138(11.5 \%)$ & $101(8.4 \%)$ & $91(7.6 \%)$ \\
\hline$\# 80,001-\# 100,000$ & $64(5.3 \%)$ & $84(7.0 \%)$ & $97(8.1 \%)$ \\
\hline$\# 100,001-\# 150,000$ & $68(5.7 \%)$ & $39(3.3 \%)$ & $85(7.1 \%)$ \\
\hline$\# 150,001-\# 200,000$ & $25(2.1 \%)$ & $23(1.9 \%)$ & $51(4.3 \%)$ \\
\hline$\# 200,001-\# 300,000$ & $13(1.1 \%)$ & $14(1.2 \%)$ & $21(1.8 \%)$ \\
\hline$>\# 300,000$ & $12(1.0 \%)$ & $24(2.0 \%)$ & $29(2.4 \%)$ \\
\hline
\end{tabular}

In the last 12 months, those that have had reasons to visit their healthcare provider (HCP) reported wide-ranging average waiting time. In Ondo State, the most reported average waiting time by 287 (23.9\%) respondent is one hour, followed by 154 (12.8\%) who reported two hours and 149 (12.4\%) who reported thirty minutes average waiting time. In Ekiti State, 214 $(17.8 \%)$ reported thirty minutes average waiting time, followed by 174 (14.5\%) who reported one hour and 115 (9.6\%) respondents that reported two hours average waiting period. In Osun State, 251 (20.9\%), 185 (15.4\%) and 169 (14.1\%) of the respondents reported average waiting time of one hour, two hours and thirty minutes respectively. Respondents that are covered by health insurance plan in all three states are either registered with the government-owned National Health Insurance Scheme (NHIS) or Health Management Organization (HMO) that provides managed care for health insurance, with the managed care being a system of health care delivery that manages the cost of healthcare, the quality of the health care and access to such care. Those not covered by any health insurance plan are mainly due to nonprovision by employer or individual/ organizational financial constraints.

In all the three states, the healthcare providers (HCPs) used by the respondents are more in the public than private health institution. The ratio of public to private sector in Ondo, Ekiti and Osun are 717 (59.8\%) to 299 (24.9\%), 769 (64.1\%) to 287 (23.9\%) and 750 
Table 4: Information About Medical Check-Up Parameters

\begin{tabular}{|c|c|c|c|c|c|c|}
\hline \multirow{2}{*}{$\begin{array}{l}\text { Source of information on } \\
\text { periodic medical check-up }\end{array}$} & \multicolumn{2}{|c|}{ ONDO STATE } & \multicolumn{2}{|c|}{ EKITI STATE } & \multicolumn{2}{|c|}{ OSUN STATE } \\
\hline & Frequency & Percentage & Frequency & Percentage & Frequency & Percentage \\
\hline Radio & 56 & $4.7 \%$ & 134 & $11.2 \%$ & 120 & $10.0 \%$ \\
\hline Television & 79 & $6.6 \%$ & 145 & $12.1 \%$ & 122 & $10.2 \%$ \\
\hline Newspaper & 112 & $9.3 \%$ & 128 & $10.7 \%$ & 119 & $9.9 \%$ \\
\hline Health Worker & 724 & $60.3 \%$ & 511 & $42.6 \%$ & 574 & $47.8 \%$ \\
\hline Family & 85 & $7.1 \%$ & 56 & $4.7 \%$ & 68 & $5.7 \%$ \\
\hline Friend & 47 & $3.9 \%$ & 49 & $4.1 \%$ & 36 & $3.0 \%$ \\
\hline $\begin{array}{c}\text { Major types of medical check- } \\
\text { up known by respondents }\end{array}$ & \multicolumn{2}{|c|}{ ONDO STATE } & \multicolumn{2}{|c|}{ EKITI STATE } & \multicolumn{2}{|c|}{ OSUN STATE } \\
\hline Eye check & 22 & $1.8 \%$ & 53 & $4.4 \%$ & 53 & $4.4 \%$ \\
\hline Dental check & 26 & $2.2 \%$ & 38 & $3.2 \%$ & 31 & $2.6 \%$ \\
\hline Urine test & 52 & $4.3 \%$ & 40 & $3.3 \%$ & 36 & $3.0 \%$ \\
\hline Blood Sugar & 19 & $1.6 \%$ & 23 & $1.9 \%$ & 50 & $4.2 \%$ \\
\hline Breast Examination & 14 & $1.2 \%$ & 29 & $2.4 \%$ & 39 & $3.3 \%$ \\
\hline Blood Pressure & 39 & $3.3 \%$ & 46 & $3.8 \%$ & 61 & $5.1 \%$ \\
\hline Pulse Rate & 22 & $1.8 \%$ & 29 & $2.4 \%$ & 39 & $3.3 \%$ \\
\hline Temperature Check & 24 & $2.0 \%$ & 59 & $4.9 \%$ & 31 & $2.6 \%$ \\
\hline HIV Retroviral Screening & 76 & $6.3 \%$ & 85 & $7.1 \%$ & 98 & $8.2 \%$ \\
\hline General Medical Check-up & 500 & $41.7 \%$ & 394 & $32.8 \%$ & 660 & $55.0 \%$ \\
\hline $\begin{array}{c}\text { Medical check-up done by } \\
\text { respondents }\end{array}$ & \multicolumn{2}{|c|}{ ONDO STATE } & \multicolumn{2}{|c|}{ EKITI STATE } & \multicolumn{2}{|c|}{ OSUN STATE } \\
\hline Eye check & 41 & $3.4 \%$ & 42 & $3.5 \%$ & 30 & $2.5 \%$ \\
\hline Dental check & 23 & $1.9 \%$ & 43 & $3.6 \%$ & 29 & $2.4 \%$ \\
\hline Urine test & 19 & $1.6 \%$ & 26 & $2.2 \%$ & 26 & $2.2 \%$ \\
\hline Kidney Function Test & 15 & $1.3 \%$ & 24 & $2.0 \%$ & 25 & $2.1 \%$ \\
\hline Liver Function Test & 14 & $1.2 \%$ & 25 & $2.1 \%$ & 20 & $1.7 \%$ \\
\hline Lipid Profile & 28 & $2.3 \%$ & 20 & $1.7 \%$ & 38 & $3.2 \%$ \\
\hline Heart Function Test & 16 & $1.3 \%$ & 18 & $1.5 \%$ & 25 & $2.1 \%$ \\
\hline Blood Sugar & 35 & $2.9 \%$ & 48 & $4.0 \%$ & 54 & $4.5 \%$ \\
\hline Breast Examination & 23 & $1.9 \%$ & 40 & $3.3 \%$ & 50 & $4.2 \%$ \\
\hline Blood Pressure & 119 & $9.9 \%$ & 96 & $8.0 \%$ & 83 & $6.9 \%$ \\
\hline Pulse Rate & 36 & $3.0 \%$ & 25 & $2.1 \%$ & 43 & $3.6 \%$ \\
\hline Temperature Check & 41 & $3.4 \%$ & 38 & $3.2 \%$ & 48 & $4.0 \%$ \\
\hline HIV Retroviral Screening & 66 & $5.5 \%$ & 91 & $7.6 \%$ & 86 & $7.2 \%$ \\
\hline General Medical Check-up & 124 & $10.3 \%$ & 149 & $12.4 \%$ & 208 & $17.3 \%$ \\
\hline $\begin{array}{l}\text { Medical check-up done } \\
\text { recommendation }\end{array}$ & \multicolumn{2}{|c|}{ ONDO STATE } & \multicolumn{2}{|c|}{ EKITI STATE } & \multicolumn{2}{|c|}{ OSUN STATE } \\
\hline Physician & 247 & $20.6 \%$ & 362 & $30.2 \%$ & 272 & $22.7 \%$ \\
\hline Nurse & 72 & $6.0 \%$ & 90 & $7.5 \%$ & 79 & $6.6 \%$ \\
\hline Other Health Professionals & 44 & $3.7 \%$ & 68 & $5.7 \%$ & 87 & $7.3 \%$ \\
\hline Self & 41 & $3.4 \%$ & 97 & $8.1 \%$ & 69 & $5.8 \%$ \\
\hline Last medical check-up done & \multicolumn{2}{|c|}{ ONDO STATE } & \multicolumn{2}{|c|}{ EKITI STATE } & \multicolumn{2}{|c|}{ OSUN STATE } \\
\hline 1 month ago & 58 & $4.8 \%$ & 114 & $9.5 \%$ & 73 & $6.1 \%$ \\
\hline 3 months ago & 34 & $2.8 \%$ & 48 & $4.0 \%$ & 68 & $5.7 \%$ \\
\hline 6 months ago & 39 & $3.3 \%$ & 33 & $2.8 \%$ & 41 & $3.4 \%$ \\
\hline 1 year ago & 49 & $4.1 \%$ & 71 & $5.9 \%$ & 60 & $5.0 \%$ \\
\hline 2 years ago & 30 & $2.5 \%$ & 31 & $2.6 \%$ & 35 & $2.9 \%$ \\
\hline
\end{tabular}


(62.5\%) to 304 (25.\%) ' respectively. Across the three states, those that felt males need the check-up more than females stated reasons mainly including the involvement of males in more strenuous day to day activities and ensuring common diseases in older males such as prostate cancer, among others, are constantly monitored while those that favoured females for more checkup than males stated it is because females are probably prone to more infections, due to menstrual cycle, pregnancy, general female body physiology, monitoring diseases more common in females such as breast and cervical cancers, etcetera.

\section{DISCUSSION}

The outcome of this study in table 1 shows that most of the respondents are aware of periodic medical check-up across the three states, which may probably be as a result of their formal education, with a large proportion of them having minimum of ordinary diploma, higher diploma or degree certificate. This is similar to the 2012 study that reported $74.9 \%$ were aware of periodic medical check-up [7]. Our findings reveal that respondents in Ekiti State have had the most deliberate routine periodic medical check-up than the other two states showing a huge priority probably placed on health by residents. Large proportion of the respondents felt everybody needs medical check-up. This is due to the fact that majority of them are educated to a large extent and possibly knowledgeable about the subject matter. Across the three states, majority of the respondents, think three monthly periodic medical check-up is adequate while maority' in Osun State feel it should be done monthly. This may ust be a matter of preference of respondents. The outcome in Osun State is slightly in keeping with the 2012 study that reported $59.9 \%$ felt that monthly check-up is good enough but the findings in Ondo \& Ekiti States are in contrast [7]. Less than one-quarter of the respondents across the states reportedly covered by health insurance plan and further fewer having periodic medical check-up included in their plan is an indication that most people still don't have a managed care provision let alone the easy access or even qualitative healthcare. The most reported average waiting time in Ondo \& Osun as well as a faster waiting time in Ekiti is indicative of a slightly effective healthcare system which might be due to insufficient workforce leading to overwhelming duty or could be as a result of low morale of workers due to unsatisfactory working conditions ' among others. More effort will thus be required from all concerned to improve turn-around-time (TAT) in order to achieve more qualitative and better healthcare delivery. The overall average monthly income in all three states as detailed in table 3 , shows that it will be an uphill task for most people not having health insurance plan to be able to make provision for such because there is high tendency that their income is not even adequate to cater for basic needs including feeding, shelter and clothing.

In all the three states, our findings revealed regarding the most important or commonest source of information on periodic medical check-up, as shown in table 4 , is however not surprising because most of the respondents seek advice from their health care providers in the hospital at time interval following visit to the hospital. The major type of medical checkup known by respondents in the states is the general medical check-up of varying grade. Also, most of the medical check-up was recommended expectedly by a physician. But while many are aware of the medical check-up, only few seem to be practising it, as shown in an aspect of table 4 . This poor practice might be mainly attributed to low income, nonprovision of such benefit by employers. This finding is similar to the outcome of certain 
previous other studies around the country and the world $[7,8,9]$.

\section{CONCLUSION}

In conclusion, there is high level of awareness of periodic medical check-up in all three states but the level of practice of routine medical check-up is low. The majority of the respondents probably don't practice it because their health insurance plan does not cover the medical check-up or due to individual/organizational financial constraints. Thus, there is need for government to promote more affordable healthcare delivery and intensify effort on public enlightenment programs \& better health information to the entire populace especially as there is a significant relationship between educational status and periodic medical check-up, in order to promote the practice of routine check-up.

Table 5: Relationship Between Educational Status \& Practice Of Periodic Medical Check-Up

\begin{tabular}{|c|c|c|c|c|c|c|c|c|c|c|c|c|}
\hline \multicolumn{13}{|c|}{ Practice of periodic medical check-up } \\
\hline & \multicolumn{4}{|c|}{ ONDO STATE } & \multicolumn{4}{|c|}{ EKITI STATE } & \multicolumn{4}{|c|}{ OSUN STATE } \\
\hline & Yes & No & NR & Total & Yes & No & NR & Total & Yes & No & NR & Total \\
\hline \multicolumn{13}{|l|}{ Educational Status } \\
\hline No formal education & 34 & 72 & 7 & 113 & 9 & 29 & 9 & 47 & 10 & 20 & 27 & 57 \\
\hline Primary education & 45 & 105 & 21 & 171 & 26 & 52 & 6 & 84 & 21 & 20 & 29 & 70 \\
\hline Secondary education & 78 & 174 & 19 & 271 & 108 & 98 & 25 & 231 & 28 & 36 & 58 & 122 \\
\hline NCE/OND & 100 & 192 & 28 & 320 & 237 & 129 & 36 & 402 & 116 & 144 & 90 & 350 \\
\hline $\mathrm{HND} / \mathrm{BSc}$ & 70 & 111 & 14 & 195 & 194 & 112 & 5 & 311 & 203 & 184 & 83 & 470 \\
\hline MSc & 14 & 27 & 5 & 46 & 27 & 21 & 3 & 51 & 41 & 34 & 8 & 83 \\
\hline $\mathrm{PhD}$ & 12 & 13 & 7 & 32 & 23 & 5 & 3 & 31 & 15 & 3 & 18 & 36 \\
\hline Status not stated & 0 & 0 & 52 & 52 & 0 & 0 & 43 & 43 & 0 & 0 & 12 & 12 \\
\hline \multirow[t]{2}{*}{ Total } & 353 & 694 & 153 & 1200 & 624 & 446 & 130 & 1200 & 434 & 441 & 325 & 1200 \\
\hline & \multicolumn{4}{|c|}{$\chi^{2}=561.491, \mathrm{p}$-value $=0.001$} & \multicolumn{4}{|c|}{$\chi^{2}=849.769, p-$ value $=0.001$} & \multicolumn{4}{|c|}{$\chi^{2}=82.306, p$-value $=0.001$} \\
\hline
\end{tabular}

The relationship between educational status and practice of periodic medical check-up is statistically significant at $\mathrm{P}<0.05$ across the three states.

NCE is National Certificate in Education OND is

Ordinary National Diploma HND is Higher

National Diploma

NR is No Response 


\section{REFERENCES}

1. Si S, Moss J, Sullivan T, Newton S, Stocks N. Effectiveness of general practice-based health checks: a systematic review and meta-analysis. Br. J. Gen. Prac. 2014; 64 (618): e47 -53 .

2. United Nations Population Fund (UNFPA). United Nations World Population Prospects. 2012 revision.

3. World Health Organization (WHO). Towards a strategy for cancer control in the Eastern Mediterranean Region, 1st ed. Cairo, World Health Organization Regional Office for the Eastern Mediterranean, 2010.

4. Moser K, Patnick J, Beral V. Inequalities in reported use of breast and cervical screening in Great Britain: analysis of cross sectional survey data. BMJ 2009; 338: b2025.

5. Si-qing L. Importance of regular physical examination for early prevention and treatment of disease in middle aged and elderly people. Chin J Convalescent Med. 2009; 14 (5):429-430.

6. WHO. Innovative Care for Chronic Conditions: Building
Blocks for Action. Geneva, Switzerland: WHO; 2002.

7. Eke CO, Eke NO, Joe-lkechebelu NN, Okoye SC. Perception and Practice of Periodic Medical Checkup by Traders in South East Nigeria. Afrimedic J. 2012; 3 (2).

8. Ilesanmi OS, Omotoso B, Alele F \& Amenkhienan I. Periodic Medical Checkup: Knowledge and Practice in a Community in South West Nigeria. Intl J Pub Health Res. 2015; 5 (1): 576 - 583.

9. Dalton ARH, Bottle RA, Okoro C, Majeed FA, Millett C: Uptake of the NHS health checks programme in a deprived, culturally diverse setting: cross sectional study. J Epid Comm Health. 2011; 65: A21.

10. Fisher RA. Statistical methods for research workers. Oliver and Boyd 1954, ISBN 0-05-002170-2.

11. Daniel WW. Biostatistics: A Foundation for Analysis in the Health Sciences, 10th ed. 2013.

12. Online Sample Size Calculator. http://www.surveysystem.com/sscalc.htm 